\title{
WRITING PROMPTS: GENERATING ENGAGEMENT, CRITICAL THINKING and DISCOVERY
}

\begin{abstract}
Sandi Van Lieu
This paper focuses on a pedagogical and instructional approach to engaging students in the classroom with the specific activ-

ity of a writing prompt, which utilizes a short video about current events and trends coupled with writing and discussion. This

strategy allows active student learning in which the students engage, develop critical thinking skills, discover topics that interest

them, improve their writing skills, prepare to be active in class, collaborate through discussion, discover other views, relate the

activity to the current course curriculum and apply the issues to their personal and professional lives. The examples given in
\end{abstract}

this paper are from English composition courses, however, this method could be applied and tailored to a variety of disciplines.

In college and university general education courses, instructors often struggle with engaging learners, including in large classrooms (generally twenty-five students or more) (Mulryan-Kyne, 2010). In addition, students lack critical thinking skills, or students do not feel they can critically think (Woodlief, 1997). When it comes to writing, students can get frustrated trying to come up with topics to write about or being assigned topics that are uninteresting to them or do not appeal to their interests (Hillocks, 1995; Freisinger, 1978). Even if they have a topic, many students lack the writing skills necessarily for the college level (Hillocks, 1994; Gleason, 2001; Drew \& Yost, 2009; Montagne, 2012) or fear the traditional lecture, memorize, test teaching-centered classroom (Hazim, Almir, \& Amir, 2008). Students can also come into class unmotivated to be active and engaged or have a surface-level approach to learning (Smart, Witt, \& Scott, 2012; Wang, Su, Cheung, Wong, \& Kwong, 2013). Not only can they be unmotivated individually, but also students can sometimes initially dislike the idea of class discussion, peer collaboration and/or speaking up in discussion (McFarlane, 2010; Montagne, 2012). Instructors may find it difficult to find an introductory class technique that also relates to the current curriculum and promotes studentcentered learning (Mintz, n.d.).

These common first-year problems can be minimized by using active, inductive instruction and using a student-learner approach to teach- ing (Smart, Witt, \& Scott, 2012; Hazim, Almir, \& Amir, 2008; Wang, Su, Cheung, Wong, \& Kwong, 2013; Biggs, 1996). Constructivism theory is based on the concept that learners should reflect on one's own thoughts and experiences as well as on other learners' thoughts - students should learn from the world around them and their interaction with peers (Biggs, 1996). This instruction should focus on 'why' and 'how,' by actively engaging in discussion, argument and collaboration to solve problems (Smart, Witt, \& Scott, 2012; Ruey, 2010; Hazim, Almir, \& Amir, 2008; Biggs, 1996; Pepper, Blackwell, Monroe, \& Coskey, 2012). In addition, specific learning activities should be self-controlled in which the learner extracts meaning from what is being presented (Biggs, 1996). To engage in a studentlearner approach in my composition classrooms, I use a writing prompt activity at the beginning of each class session. This article discusses the specifics of the activity and the student learning outcomes the activity produces.

\section{METHOD}

At the beginning of each college composition class session, a short video is shown that was located on the Internet. These videos range from TED talks ("TED," n.d.) to news clips, to RSA Animates ("RSA," n.d.). If there is a current event, it is believed that the students will show interest in it, if a video is shown in conjunction with the discussion (Hazim, Almir, \& Amir, 2008; Biggs, 1996). For 
example, when the controversial Arizona proposal SB1070 was occurring (anti-illegal immigration legislation), the faculty member showed a news clip about the debate. Inductive learning often means that the instructor assesses what the students know and then works to construct new knowledge (Smart, Witt, \& Scott, 2012), so in this specific case, the students new the issue was going on in their state, but they did not all know the various arguments and viewpoints about the issue.

In addition to current events, faculty may show videos that relate to pop culture issues, topics and trends it is believed that most of the class discussed herein are at an age group that would care about media or video in relation to current events and topics (Hazim, Almir, \& Amir, 2008; Stuckey \& Kring, 2007; Biggs, 1996; Montagne, 2012). The students should "analyze and generalize and then find ways to apply the conclusions in solving real-world problems" (Smart, Witt, \& Scott, 2012, p. 393; Stuckey \& Kring, 2007; Boyd, WilliamsBlack, \& Love, 2009). For example, one semester when a famous singer made nation-wide news with what was suggested by many in the public to be an inappropriate awards-show performance; it was used in class as a writing prompt. At the end of the semester, students noted it was one of their favorite writing prompts because not only was it a pop cultural issue they were familiar with, but the writing and discussion made them think about issues of modesty, the media, role models and what mothers and fathers teach their children. Viewing videos on pop culture issues with a critical eye can allow students to examine critically "to gain a deeper knowledge of the process and the content of the material" (Stuckey \& Kring, 2007, p. 32) and it can allow them to engage in a creative process that helps construct meaning and express their individual views of their selves and the world (Faulkner, 2003; Boyd, Williams-Black, \& Love, 2009), much of which correlates to adult learning theory (Montagne, 2012).

In addition to state/national news and pop culture, video clips are used in class that address general, yet interesting topics and social issues (Stuckey \& Kring, 2007; Faulkner, 2003; Montagne, 2012), because pop cultural vehicles can engage students into discourse as well as into reflective thinking that offers connections to formal and informal literacy (Faulkner, 2003). In class videos have been shown on the topics of dating relationships, friendships, honesty/dishonesty, empathy, bullying, depression, eating disorders, motivation, advertising, technology and women in media. End-of-the-semester student polls in the past for this activity, note that the most popular writing prompts are ones related to pop culture, relationships and college issues such as procrastination and this is not a surprising find if the instructor understands his or her students' curiosity and interests (Hazim, Almir, \& Amir, 2008; Stuckey \& Kring, 2007; Biggs, 1996; Drew \& Yost, 2009; Montagne, 2012).

After the video is over, students are asked to write freely about the topic for five minutes on their laptops. In case the students cannot think of what to start writing about, a PowerPoint slide is provided, which lists probing questions they can answer through their brainstorming process. This is critical because learning theory suggests that questions in the classroom (both asking the students and having the students pose their own) lead them to construct knowledge, store knowledge and retrieve knowledge (Smart, Witt, \& Scott, 2012). Often leading questions force students to think about the writing prompt issue in terms of the type of essay they are working on, thus making connections (Larson \& Lovelace, 2013; Rule, 2013; Drew \& Yost, 2009). For example, if they are working on a causal essay, the instructor might ask what the causes of the issue is. If they are working on using statistics in their essay and the video talks about the staggering statistics of social media, the instructor could consider what questions need to be asked about the studies behind the statistics (For further examples of writing prompt videos, topics and questions, see Appendix A). Finally, it is important that the questions force the students to analyze, synthesis and/ or evaluate the topic as these are the facets of active learning (Middleton, 2012; Stuckey \& Kring, 2007) and they can lead to more effective freewriting (Rule, 2013).

Once the students are finished writing, they spend a few minutes discussing the topic. If the discussion becomes "hot" with several students raising hands and volunteering to speak, they are allowed to discuss, ask questions and keep the conversation going (Hazim, Almir, \& Amir, 2008; Biggs, 1996; Pepper, Blackwell, Monroe, \& Coskey, 2012). If few students are talking, faculty will engage the students by asking them their thoughts 
on the issue (Rule, 2013). Using popular culture as a tool for discussion can be an effective way for students to construct new knowledge and bring their own experiences to the classroom (Stuckey \& Kring, 2007; Montagne, 2012).

Finally, the writing prompts are monitored over a period of time, granting participation credit for completing the activity (Bean, 2011). When it comes to curriculum in composition courses, students should be writing a lot and for instructors this can mean more writing and grading as well. However, just because writing is required, does not mean faculty have to grade it all. In fact, as Elbow (1994) notes, "Students won't write enough unless we assign more writing than we can comment on-or even read" (p. 7). Therefore, creating writing prompts as a low-stakes assignment can allow the students to write more, thereby meeting objectives, while keeping instructor grading reasonable (Bean, 2011).

\section{THEORETICAL FRAMEWORK}

Elbow (1997) would refer to a classroom writing prompt activity as low-stakes writing. The goal is "not so much to produce excellent pieces of writing as to get students to think, learn and understand more of the course material" (p. 5). Lowstakes writing is informal and usually graded as such (Bean, 2011). High-stakes writing - in which instructors grade and judge student writing - is, of course, necessary as well (Bean, 2011). However, instructors often focus on high-stakes writing while overlooking the value of low-stakes writing (Bean, 2011). Low-stakes writing is beneficial because it allows students to express themselves without fear of doing it "incorrectly" in terms of mechanics and clarity; prose is often more natural and tangible; it can improve high-stakes writing; and it can give instructors a view of how students are understanding the course material (Elbow, 1997; Bean, 2011; Drew \& Yost, 2009; Ireland, 2011).

Often students - no matter their writing level-have a fear of writing (Elbow, 1973) or fear high-stakes memorization and testing that does not allow for creative assignments to be graded (Hazim, Almir, \& Amir, 2008; Drew \& Yost, 2009). Elbow (1973) argues that people in general view their relationship to the process of writing as one of "helplessness" (p. 12). In addition, many students perceive writing as boring or not understand- ing the purpose (Freisinger, 1978; Hazim, Almir, \& Amir, 2008). Freisinger (1978) explains that, "If we can help students rediscover words as a creative medium, a means to pleasure and a tool for original expression, they may come to see that writing is fun and that it matters" (p. 284). This is when low-stakes expressive writing as a form of active learning can come into play (Elbow, 1994; Ireland, 2011; Pepper, Blackwell, Monroe, \& Coskey, 2012; Boyd, Williams-Black, \& Love, 2009).

Students can effectively write when instruction "considers what students know, uses that to engage them in more complex procedures, provides support of various kinds and allows them to become active learners" (Hillocks, 1995, p. 23). Expressive writing allows students to zone in on content and thought and it determines the student's "thought processes as the written text is produced" (Britton, 1975, pp. 30-31). It should focus on content rather than an overemphasis of rules of English (Freisinger, 1978; Bean, 2011; Ireland, 2011; Drew \& Yost, 2009). While traditional English teachers may cringe at this, it is a critical part of the English composition classroom. Freisinger (1980) argues that schools' "neglect of the learning function of language and their excessive concern for the transactional function may be largely responsible for the cognitive impairment of a significant number of our students" (p. 162). In addition, connecting to students' prior knowledge is key to learning (Smart, Witt, \& Scott, 2012; Ruey, 2010; Montagne, 2012).

Expressive writing is most useful at the beginning of a demanding writing task (Ireland, 2011). During expressive writing, the student "moves outward from an expressive phase toward transactional writing, which is the terminal point of a complex, messy, recursive process" (Fresinger, 1980, p. 162; Drew \& Yost, 2009; Ireland, 2011). This type of writing coupled with positive feedback leads to students relaxing and improving writing in what they feel "is a safe environment to play with language" (Hess, 2011, para. 6; Bean, 2011; Hamilton, 2012; Ireland, 2011).

Active learning in the college classroom is important (Dewey, 1916, as cited by Pepper, Blackwell, Monroe, \& Coskey, 2012). Active learning strategies give students the "opportunity to experience and interact with the curriculum to answer questions and solve problems... [and] the teacher should serve as facilitator and guide students to discover 
meaning in the skills or concepts to be learned" (p. 2). Students listen, reflect, write and talk to problem-solve in creative ways (Middleton, 2013; Hazim, Almir, \& Amir, 2008). When students are engaged in a "deep" approach to learning, this can be tied to higher levels of academic achievement. In order to facilitate a deep approach, instructors have to aim for meaningful learning and focus on clear goals while fostering independence (Wang, $\mathrm{Su}$, Cheung, Wong, \& Kwong, 2013). Exploratory writing done in an active learning context helps with writing skills, critical thinking skills and discovery and can be valuable to the students even if they are not graded (Elbow, 1997; Woodlief, 1997; Middleton, 2013; Bean, 2011).

\section{RESULTS: EIGHT POSITIVE ATTRIBUTES}

Conducting the writing prompt activity over the years with first-year composition students has resulted in the following eight positive attributes:

1. Engagement. The use of videos is usually an immediate form of engagement with students. It is noted that the majority of the students are watching and paying attention to the video when it is shown and they appear engaged. With various learning styles in a classroom, technology often appeals to many of them. Using technology in composition classrooms can lead to enhanced learning and students often prefer various types of technological learning objects (Mulryan-Kyne, 2010; Madigan, n.d.; Mestre, 2010) and meaningful technological integration into the classroom is conducted by giving the students tasks that intentionally and actively help the students think about experiences and thus construct meaning (Xu, Park, \& Baek, 2011; Stuckey \& Kring, 2007). Furthermore, not only are the videos a positive way to integrate technology into the classroom, but in addition, the use of laptops and the students typing their responses is enforced as a way of learning (Zhu, Kaplan, Dershimer, \& Bergon, 2011). Video choice is crucial. It is important to select time-sensitive and interesting ones (Stuckey \& Kring, 2007; Hazim, Almir, \& Amir, 2008). Some of the students' favorite videos are produced by RSA Animate in which an expert explains the issue while a quick white-board drawing in the form of animation happens simultaneously ("RSA," n.d.). Some of the videos are emotional, creative, or include speakers who use humor, all of which reinforce the level of engagement from the student.

2. Critical thinking. It is believed many students in first-year composition college courses do not value critical thinking (Hamilton, 2012; Carlson, 2013). Instructors may view critical thinking as one of the most important-if not the most important_value of education (McGown, 2011; Carlson, 2013; Bean, 2011), while students tend to complain about the task and thus instructors get frustrated by this gap (Carlson, 2013). One of student complaints with critical thinking, is that they feel it cannot help them outside of the classroom (Woodlief, 1997; Carlson, 2013). Presenting topics through the means of videos can help students see that they can use critical thinking outside the classroom as they discuss and analyze topics that they deal with on a daily basis (Middleton, 2013; Stuckey \& Kring, 2007; Boyd, WilliamsBlack, \& Love, 2009). In addition, the videos that deal with current events keep the students abreast on important issues and students often feel more informed on those debates after class discussions. The greatest impact in a discussion environment is that in which the students' ideas are at the forefront and the goal is not to find a correct solution to the issue/topic (Hillocks, 1995; Hazim, Almir, \& Amir, 2008; Hamilton, 2012; Pepper, Blackwell, Monroe, \& Coskey, 2012). The teacher's role is to "coach and prompt, to ask questions that push at the edges of student ideas and to sustain the interchange among students" (Hillocks, 1995 , p. 65). The group discussions after the videos and the writings allow for such critical thinking as is a central part of effective active learning (Middleton, 2013; Hazim, Almir, \& Amir, 2008; Pepper, Blackwell, Monroe, \& Coskey, 2012; Bean, 2011).

3. Discovery. Since all of the videos are different and cover various issues, they allow the students to discover which topics inter- 
est them and are important to them. Several times after the videos, students decide to write their essay on that writing prompt's topic, because it spiked their interest. Bean (2011) notes that teachers need to "adopt teaching strategies that give students repeated, active practice at exploring disciplinary questions and problems" (p. 38). Students can be more successful in writing when the instructor allows them to pose questions and explore issues rather than being told to choose and narrow a topic (Bean, 2011; Hamilton, 2012, Ireland, 2011). This discovery of writing topics is a critical part of my composition classroom, because, "If composition classes allow students to write about subjects which matter to them, composition teachers can also assure (convince) their composition students of the therapeutic value of said writing" (Hess, 2011, para. 4). In turn there will be no vulnerability in writing by "assigning sanitized and prepackaged essay topics and patterns that have no reality or relevance for most students" (Freisinger, 1978, p. 284). Assignments and topic choices in a composition class should accommodate the wide range of students' passions and interests (Hess, 2011), thus the writing prompts allow for such discovery.

4. Writing skills. Perhaps one of the most obvious benefits of the writing prompt activity is that the students improve their writing skills. Research supports journal writing in the higher education classroom, because the students are not constricted to a format, plan, or grammar conventions and yet all of these areas are improved through the use of free writing (Elbow, 1997; Bean, 2011; Dunlap, 2006). One of the most significant characteristics about free writing is that there is no editing during the process. Instead, a writer simply puts words down on the page and practices regularly "it undoes the ingrained habit of editing at the same time you are trying to produce. It will make writing less blocked because words will come more easily" (Elbow, 1973, p. 6). Free writing brings forth many ideas as "a transaction with words whereby you free yourself from what you presently think, feel and perceive. You make available to yourself something better than what you'd be stuck with if you'd actually succeeded in making your meaning clear at the start" (Elbow, 1973, p. 15).

5. Class preparation. Having the writing prompt at the beginning of class often gets the students ready to start. They have written, thought, discussed and often appear more "awake" and engaged for class once the exercise is over. In addition, the writing prompt appeals to student's passions and motives. While on the onset of a composition course a student may not believe he or she has a motive beyond it being a requirement, faculty can help them discover their motives (Freisinger, 1978; Bean, 2011; Smart, Witt, \& Scott, 2012). The writing prompts often bring forth those motives.

6. Collaboration. As a class writing prompts were discussed and because of this, students often discover new and different views other than their own (Middleton, 2013; Hazim, Almir, \& Amir, 2008). The discussion leads to students "piggy-backing" and adding on to what the previous student said, as well as giving examples; however, it also allows for the instructor to engage and lead in case the collaboration is offtrack or one-dimensional (Hamilton, 2012). In addition, when students later peer-edit essays in class, they address critical thinking and logical/illogical arguments within one another's essays. As Elbow (1994) emphasizes, "Writing can have a powerful communal or social dimension; it doesn't have to feel solitary" (p. 7). Students need to talk about their ideas in groups (Middleton, 2013; Hazim, Almir, \& Amir, 2008; Hamilton, 2012; Pepper, Blackwell, Monroe, \& Coskey, 2012) and "bounce ideas off interested listeners, to test arguments, to see how audiences react" (Bean, 2011, p. 36).

7. Connection. While the video topics may seem random, often the themes, questions and answers, from the writing prompts relate or connect to the current curriculum 
or other disciplines (Bean, 2011; Drew \& Yost, 2009). For example, questions on the writing prompt PowerPoint slide might address the type of essay they are working on (definition, causal, proposal, argumentative and so forth). In addition, as students give arguments, they begin to see if those arguments are logical and can be supported. Through the connection aspect, students are to connect to their selves and the world around them in a deep way (Middleton, 2013; Hamilton, 2012).

8. Personal values. Because many of the videos deal with emotional and personal issues (i.e., honesty, empathy, relationships, finances and so forth), the students often note in their end-of-the-semester reflection that they have taken away personal values (See table). This type of writing encourages students to bring in their own experiences and link the writing to them (Middleton, 2013). Writing is therapeutic and while one must not, turn a composition classroom into a counseling session, faculty should be able to recognize the psychological value of writing. If students write simply to get a grade, "if they are not engaged with the process of writing, there can be no real therapeutic value," because then "the writing connects not to the mind or the spirit or the unconscious, but only to the wrist. It is passionless, uncreative and it will mean little to students" (Freisinger, 1978, p. 284). Personal values are significant predecessors of behavior and therefore students should examine their values before applying them to their career world (Middleton, 2013; Boyd, Williams-Black, \& Love, 2009).

On the issue of careers, the video topics sometimes deal with issues students can apply to their future careers (ethics, work motivation, psychology, \& sociology,), or allow them to connect to the world around them, which is an important attribute of active learning (Middleton, 2013; Boyd, Williams-Black, \& Love, 2009). Expressive writing has been shown by researchers to be a foundation for "learning, writing with engagement and developing a strong 'transactional' or public voice" (Britton, 1975, as cited in Freisinger, 1978, p. 283; Bean, 2011). If faculty make composition writing more than a simple "requirement" course, then they can show students that "writing is an indispensable tool for shaping personal and professional identities" (Freisinger, 1978, p. 285). Students can "learn first-hand the purchase writing can give them on their emerging selves and careers" (Freisinger, 1978, 285). Pedagogy should provoke students "to see their writing as the vehicle by which they communicate with a larger community" (Dunbar-Odom, 2010, p. 172). When students are drawing conclusions and questioning how they see themselves in the world this is the "setting most conducive to helping students also make connections between their own experience and the much larger world" (Dunbar-Odom, 2010, p. 172).

\section{STUDENT REFLECTIONS ON WRITING PROMPTS}

The writing prompt exercise can serve as a form of active learning to make composition courses "more attractive and authentic" while also bringing forth better writing (Freisinger, 1978, p. 285; Bean, 2011). The overwhelming majority students from semester to semester note their enjoyment of the writing prompts. The following are student comments as they relate to the aforementioned eight positive attributes:

\section{Engagement}

- I like how they are not boring and keep me very interested.

- The videos are almost always emotionally stimulating. The topics always contain videos that speak about an issue and they are often very moving and motivational (personal communication, March 11, 2014).

2. Critical thinking

- I grow through writing prompts by thinking through different topics and coming to conclusions about them. It opens me up to the things going on around the world and makes me an active thinker.

- Writing prompts lead me to wonder about certain beliefs I hold and why are they valid or not. It is easy to live every day without consciously knowing the reasons behind our behaviors and patterns of our worldview and by stopping for a few minutes to consider a concept or issue, it enables us to establish a stronger foundation for who we are and what we hold onto as truth (personal communication, March 11, 2014). 
3. Discovery

- It allows me to have time to reflect on things and write about a topic that interests me.

- Writing prompts helped educate me on various topics and created in me a greater passion to learn and write about things that matter (personal communication, March 11, 2014).

4. Writing skills

- The writing prompts offer me the opportunity to expand my writing techniques and offer me new perspectives to my style of writing. Sometimes when writing an essay I become so wrapped up in the topic and almost stuck but then writing prompts allow me to switch to a different topic and style which makes it easier to look at my essay from a different perspective.

- The more I wrote, the better I became at communicating my ideas. In completing these writing prompts, I have not only improved my writing style but my brainstorming technique as well. Now I am able to free write and produce ideas much more efficiently than before (personal communication, March 11, 2014).

5. Class preparation

- It warms up my brain and I become more involved in the class.

- The writing prompts in the beginning of class allow me to settle down from the hectic morning I currently had and set myself in a learning and critical thinking mode (personal communication, March 11, 2014).

6. Collaboration

- It helps teach how to participate in discussions and how to respectfully argue.

- After I write my prompt, I love to hear what everybody else in the classroom has to say. Almost every person usually has a different opinion on the matter being discussed and this challenges my way of thinking. I grow personally by being willing to change my views on a certain matter if I believe in what someone has to say over what I wrote (personal communication, March 11, 2014).

7. Connection

- A writing prompt serves as a base for a fully constructed essay and provides helpful tools for writing an exceptional paper.
- The purpose they serve are to help me grow personally as a writer and to broaden my views on what I research or hear about (personal communication, March 11, 2014).

8. Personal values

- I really enjoy addressing the issues of the world in hope it will teach us all a little more about being kind to one another.

- Wanting to be a nurse, I have found that many of the writing prompts have allowed me to develop arguments and voice my case. This will help in nursing when I talk with parents and so forth (personal communication, March 11, 2014).

\section{SUGGESTIONS AND CONSIDERATIONS}

Through instructor writing workshops, it has been suggested that the aforementioned activity be implemented by instructors of other disciplines. The method may need to be tailored to fit the course and objectives, however, it may still be applicable and aid in student learning for other disciplines. For example, science instructors could show videos related to science issues such as current events or ethics. Psychology and sociology instructors might show videos related to human nature, current events, pop culture and so forth. Through this, students would be exploring issues within the discipline while also improving critical thinking and writing skills. This idea of cross-disciplinary writing is supported by research (Freisinger, 1980; Hamilton, 2012; Henscheid, O'Rourke, \& Williams, 2009; Simão \& Flores, 2010). Future research could explore using the writing prompt activity in various types of courses, or having the writing prompt in the English classrooms explore an issue from another discipline.

Students in previous courses have made alternative suggestions for the writing prompt, such as having more free writing opportunities, or allowing the prompts to only relate to the current essay they are working on; therefore, it goes without saying that this activity will be continued and it will be tailored it to the type of class being taught, as should other instructors who want to use a similar method.

\section{CONCLUSION}

The writing prompt activity reflects an inductive approach to learning, guided by the elements of constructivism (Biggs, 1996). This involves be- 
ginning with content familiar to students, presenting the material in a way that allows students to cognitively shift gradually, instructor leading to help fill in gaps and make connections and allowing students to teach and learn from one another (Smart, Witt, \& Scott, 2012).

One student summed up many of the previously discussed points in her reflection on writing prompts in this way:

"In a world with advancing technology, creativity is already running low, but when we are not able to write freely then it is hard to give any creativity. Writing prompts are the break from structure that lets thoughts flow from the mind to the form of medium (paper or laptop). Gears in the brain began to move producing a short vacation for the brain to think for itself, instead of having thoughts given to it. When writing a Writing Prompt you are in your own little world, where you can write what you feel and what you think without any objection from anyone around. You can defend a claim or attack it, you can let out any anger or resentment, you can even write funny things that pop into your head. Writing prompts is the immunity to be yourself and get out of the framework. Even if it's for a moment or five minutes, Writing Prompts are a form freedom" (personal communication, March 11, 2014).

\section{References}

Bean, J. C. (2011). Engaging ideas: The professor's guide to integrating writing, critical thinking and active learning in the classroom (2nd ed.). San Francisco, CA: Jossey-Bass.

Biggs, J. (1996). Enhancing teaching through constructive alignment. Higher Education, 32, 1-18. Retrieved from http:// www.are.uwa.edu.au/_data/assets/pdf_file/0003/2199045/ Biggs-1996-HE-enhancing-teaching-through-constructivealignment.pdf

Boyd, N. C., Williams-Black, T. H., \& Love, F. E. (2009). Using realworld connections to engage graduate students in authentic reading and writing. Reading Improvement, 46(4), 238-246. Accession number 48897234

Britton, J. (1975). The development of writing abilities. London, England: MacMillan.

Carlson, S. C. (2013). Instructional methods influence critical thinking: Do students and instructors agree? Academy of Educational Leadership Journal, 17(1), 27. Accession number 87744053
Drew, C., \& Yost, D. (2009). Composing creativity: Further crossing composition/creative writing boundaries. The Journal of the Midwest Modern Language Association, 42(1), 25-42. Accession Number edsjsr.25674354

Dunbar-Odom, D. (2010). Local and global: The writing class's vital role in composing citizens. Issues in Writing, 18(2), 168184. Accession Number 71931006

Dunlap, J. C. (2006). Using guided reflective journaling activities to capture students' changing perceptions. Techtrends: Linking Research and Practice to Improve Learning, 50(6), 20-26. Accession Number 23526116

Elbow, P. (1973). Writing without teachers. New York, NY: Oxford University Press, Inc.

Elbow, P. (1994). Writing for learning—not just for demonstrating learning. University of Massachusetts, Amherst, National Teaching and Learning Forum. Retrieved from: http://www. oberlin.edu/ctie/Elbow-Learning.pdf

Elbow, P. (1997). High stakes and low stakes in assigning and responding to writing. New Directions for Teaching and Learning, 69, 5-13. Accession number 9705182963

Faulkner, J. (2003). "Like you have a bubble inside of you that just wants to pop:" Popular culture, pleasure and the English classroom. English Teaching: Practice \& Critique, 2(2), 47. Accession Number 31549540

Freisinger, R. R. (1978). Creative writing and creative composition. College English, 3, 283-284. Accession number edsjsr.10.2307.375788

Freisinger, R. R. (1980). Cross-disciplinary writing workshops: Theory and practice. College English, 2(42), 154-156, 161166. Accession number edsjsr.10.2307.375838

Gleason, B. (2001). Teaching at the crossroads: Choices and challenges in college composition. The Writing Instructor. Retrieved from http://www.writinginstructor.com/reflections/ gleason.html

Hamilton, B. E. (2012). "Welcome to the communion of your race:" Hipsters, puritans and the search for meaning. Interdisciplinary Humanities, 29(2), 15-27. Accession Number 84401866

Hazim, B., Almir, P., \& Amir, P. (2008). Active learning methods in the context of higher education reform. Zbornik Radova, 28, 132-144. Accession Number 36430834

Henscheid, J., O’Rourke, M., \& Williams, G. (2009). Embedding the Humanities in Cross-Disciplinary General Education Courses. JGE: The Journal of General Education, 58(4), 279295. Accession Number 50739240 
Hess, M. (2011, June 24). Teaching composition creatively. Retrieved from http://www.lorejournal.org/2011/06/teachingcomposition-creatively/

Hillocks, G. (1995). Teaching writing as reflective practice. New York, NY: Teachers College Press.

Ireland, R. (2011). Talking to One's Self. Writing on the Edge, 21(2), 64-72. Accession Number 60305240

Larson, L. R., \& Lovelace, M. D. (2013). Evaluating the efficacy of questioning strategies in lecture-based classroom environments: Are we asking the right questions? Journal on Excellence in College Teaching, 24(1), 105-122. Accession Number 85628873

Madigan, D. (n.d.). The technology literate professoriate: Are we there yet? Bowling Green State University. Retrieved from http://ideaedu.org/sites/default/files//dea_Paper_43.pdf

McFarlane, D. A. (2010). Teaching unmotivated and under-motivated college students: Problems, challenges and considerations. College Quarterly. 13(3), 1-5. Accession number 64286945

McGowan, H. (2011). Standardized criteria and the responsibilities of the instructor in a community college English composition course. (Doctoral dissertation). Available from ProQuest Dissertations \& Theses Full Text: The Humanities and Social Sciences Collection. (Order No. 902456854)

Mestre, L. S. (2010). Matching up Learning Styles with Learning Objects: What's Effective? Journal of Library Administration, 50(7.8), 808-829. Accession Number 54302828

Mintz, S. (n.d.). The fundamentals of college and university teaching. Columbia University. Retrieved from http://gsas.columbia. edu/sites/default/files/GSAS_fundamentals_handbook.pdf

Montagne, L. (2012). Student learning outcomes and pedagogy in online and face-to-face college English composition: A mixed methods study. (Doctoral dissertation). Available from ProQuest Dissertations \& Theses Full Text: The Humanities and Social Sciences Collection. (Order No. 1049202943)

Mulryan-Kyne, C. (2010). Teaching large classes at college and university level: challenges and opportunities. Teaching In Higher Education, 15(2), 175-185. Accession number 201007669-005

Pepper, K., Blackwell, S., Monroe, A., \& Coskey, S. (2012). Transfer of active learning strategies from the teacher education classroom to preK-12th grade classrooms. Current Issues in Education, 15(3), 1-23. Accession number 88843611
RSA (n.d.). RSA animate. Retrieved from http://www.thersa.org/ events/rsaanimate

Rule, H. (2013). The difficulties of thinking through freewriting. Composition Forum, 27. Accession Number EJ1003968

Simão, A. V., \& Flores, M. A. (2010). Student-centred methods in higher education: Implications for student learning and professional development. International Journal of Learning, 17(2), 207-217. Accession Number 52791934

Smart, K. L., Witt, C., \& Scott, J. P. (2012). Toward learnercentered teaching: An inductive approach. Business Communication Quarterly, 75(4) 392-403. DOI: 10.1177/1080569912459752

Ruey, S. (2010). A case study of constructivist instructional strategies for adult online learning. British Journal of Educational Technology, 41(5), 706-720. doi:10.1111/j.14678535.2009.00965.x

TED. (n.d.). TED: Ideas worth spreading. Retrieved from https:// www.ted.com/

Wang, X., Su, Y., Cheung, S., Wong, E., \& Kwong, T. (2013). An exploration of Biggs' constructive alignment in course design and its impact on students' learning approaches. Assessment \& Evaluation in Higher Education, 38(4), 477-491, http:/l dx.doi.org/10.1080/02602938.2012.658018

Woodlief, L. K. (1997). Academic literacy in action: A qualitative case study of a college English department. (Doctoral dissertation). Retrieved from ProQuest Dissertations and Theses. (Order No. 304389374).

Xu, Y., Park, H., \& Baek, Y. (2011). A new approach toward digital storytelling: An activity focused on writing self-efficacy in a virtual learning environment. Educational Technology \& Society, 14 (4), 181-191. Accession Number 000298968800016

Zhu, E., Kaplan, M., Dershimer, R. C., \& Bergon, I. (2011). Use of laptops in the classroom: Research and best practices. Center for Research on Learning and Teaching, no. 30. Retrieved from http://www.crlt.umich.edu/sites/default/files/ resource_files/CRLT_no30.pdf 


\section{Appendix A}

\section{EXAMPLES OF WRITING PROMPTS}

\section{WRITING PROMPT 1}

Topic/Issue: Legalizing marijuana

Curriculum relation: Definition essay

Video: http://www.youtube.com/

watch? $\mathrm{v}=\mathrm{qKgY} 5 \mathrm{eO}$ lhEc

\section{QUESTIONS:}

- What is the speaker's central claim and reason?

- What are the speaker's key grounds for legalizing marijuana?

- Reflect on what you read in Chapter 11: What types of definitions does the speaker make? What categories does he put certain key terms in? What comparisons does he make?

- What rebuttals could you offer?

\section{WRITING PROMPT 2}

Topic/Issue: Social media

Curriculum relation: Using statistics

Video: http://www.youtube.com/

watch?v=sIFYPQjYhv8

\section{QUESTIONS:}

- How does social media affect you on a daily basis?

- In your future ideal career, how could you see yourself or your company using social media?

- When you are reading a study (or statistics) what types of questions should you be asking? Did any of the statistics in this video not seem right to you? Why?

- Do we let technology take over our "real" communication, or is communication just changing?

- How is social media changing business?

- How is social media changing education?

\section{WRITING PROMPT 3}

Topic/Issue: Racism; peer pressure; higher education

Curriculum relation: Argumentative essay

Videos: http://www.huffingtonpost.com/2014/01/25/ a s u - f r a t e r n i t y-m $1 \mathrm{k}-\mathrm{r}$ a c i s t - par t y expulsion_n_4666258.html

http://Www.azcentral.com/community/tempe/ articles/20140121asu-suspended-fraternity-mlkparty-draws-criticism.html

\section{QUESTIONS:}

- What do these college students' actions show about their character? As the news anchors discussed, dozens of students were involved; why did no one stand up and say it was wrong?

- Some students and others are saying the group had free speech rights and therefore should not be expelled. Do you agree or disagree?

- Banning the fraternity is one thing (especially since they were already on suspension), but expelling the students is another. Does the school have the right to expel them?

- As a college student, have you ever had to stand up to your peers about decisions that were being made? If you had to stand up, do you think you could?

\section{WRITING PROMPT 4}

Topic/Issue: Workplace motivation

Curriculum relation: Cause/Effect Essay

Video: http://www.youtube.com/ watch?v=u6XAPnuFjJc

\section{QUESTIONS:}

- What causes you to be motivated at work?

- What causes you to be motivated to go to school and to do your school work?

- When you work hard, what are the effects? (Whether at a job or at school).

- What are the effects or results of rewards on people? What about on yourself?

- What are the effects of punishments on people in jobs? In school?

- What are the possible effects of going all the way through college and graduating?

\section{WRITING PROMPT 5}

Topic/Issue: Higher education; financial aid Curriculum relation: Higher education issues

Video: http://www.youtube.com/ watch?v=ZAwBN2Q8L14 


\section{QUESTIONS:}

- What are the causes of the higher education bubble?

- What are the effects of the higher education bubble?

- Why is it important that if you take loans that you actually pass your classes and finish college?

- What are the effects of rising tuition costs? Should the states and governments do something about the rising costs of college tuition?

- In your view, so far, are college courses rigorous enough? Are they preparing you for a career?

- If experience is something employers look for when hiring, how can you be ready not only with your degree, but with experience as well?

\section{About the Author}

Sandi Van Lieu has taught literature and composition at the college level for more than a decade. She is a freelance writer and editor for books and for college curriculum. At GCU, she enjoys teaching, working with faculty and assisting in the adjunct faculty website with CIRT. She is currently earning her EdD in leadership with an emphasis in higher education and her dissertation researches the motivation for online adjunct English faculty to engage in scholarship. 